\title{
Elastin and Collagen in the Fetal Sheep Lung. I. Ontogenesis
}

\author{
JIAN-CLAUDE SCHELLENBERG AND GRAHAM C. I.ICIGINS

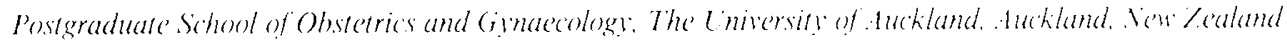

\begin{abstract}
ABSTRACI. The ontogenesis of elastin (desmosine), collagen (hydroxyproline), and $\mathrm{DN} \Lambda$ concentrations and their rates of increase were studied in fetal sheep lungs from day 60 until term. Elastin increased 13-, 17-, 63- and 11 fold in nondissected parenchyma, dissected (free of tubular structures of $>0.1 \mathrm{~mm}$ diameter) parenchyma, pleura, and trachea, respectively. Collagen increased 2.1-, 1.8-, 5- and 3 -fold, respectively, in the four tissues. $A$ sharp rise in elastin occurred after day 100 . The rate of increase in elastin was greater in dissected than in nondissected parenchyma while the reverse was true for collagen. The steepest rise of elastin concentration occurred in the pleura after day 125 . DN $A$ concentration peaked on day 125 and was lowest at term. These findings are consistent with 1 ) the onset of a steep rise in elastin accumulation during the canalicular period, 2) the development of a rigid, mainly collagenous structure of the central airways and blood vessels and a distensible peripheral "gas-exchange tissue," rich in elastin, 3) an important role of elastin in the function of the visceral pleura, and 4) a peak of mitotic activity during the early alveolar period. (Pediatr Res 22: 335-338, 1987)
\end{abstract}

\section{Abbreviation}

$R I \Lambda$, radioimmunoassay

The morphogenesis of the fetal sheep lung is well documented $(1-5)$ and it is recognized that connective tissue plays an important part in the mechanical behavior of adult lungs $(6,7)$. bat quantitative data on the connective tissue of the developing sheep lung are scant $(8,9)$. This is true even for elastin $(9,10)$, a waterinsoluble polymer (10), to which a fundamental role in alveolization has been ascribed $(11,12)$ and which has been considered for some time an important marker of lung maturity $(13,14)$. One reason for the paucity of data is the absence until recently of reliable methods for the measurement of elastin in perinatal lung (15-18). In the present study we determined elastin by measuring desmosine, a specific cross-linking amino acid, by radioimmunoassay (18). We report the concentrations of elastin, collagen, and DN $\wedge$ in well-defined areas of the fetal sheep lung between day 60 of gestation and term and compare them with the morphological features described by other workers.

\section{ME:THODS}

Animals. Sheep fetuses of gestational ages between 55 and 140 days gestation from freshly killed ewes were obtained from the

Received July 9, 1986: accepted April 17, 1987.

Correspondence Dr. J-('. Schellenterg, Postgraduate School of Obstetries and (iynaccology. National Women's Hospital. Auckland. New Zealand.

Supported by the Medical Research Council of New Zealand and the Auckland Medical Research Foundation. local abattoir (Table 1). Gestational age was determined from fetal weight. crown-rump length. and from bone age of the limbs (19.20). Term lungs were obtained from fetuses delivered by hysterotomy in pregnancies with known mating dates. The fetuses had been sham-adrenalectomized at 107 days gestation and cannulated and infused with saline at term (21). Medroxyprogesterone acetate (Depo-Provera. The Upjohn Company. Kalamazoo. MI) was given to these ewes near term to prevent spontaneous delivery. Indices of lung maturation were the same as those of intact term animals (21, 22). Lungs were removed from the thorax. weighed, and frozen. After thawing. the right lung was dissected further: each lobe was transected perpendicular to the lobe bronchus at mid-distance between its origin and its tip and $5 \mathrm{~mm}$ proximally and distally yielding two slices of 5 $\mathrm{mm}$ thickness each. The pleura was removed from all slices and pooted. The proximal slice of each lobe was dissected under a microscope and "tubular structures" removed. The "dissected" tissue, as well as the distal lung slices ("nondissected" tissue). and the pleura and the trachea (from the bifurcation to $1-2 \mathrm{~cm}$ above the right upper lobar bronchus) were refrozen. lyophilized, and dried to constant weight after pulverization. Microphotographs were taken on a grid and light microscopy was performed on dissected tissue. No cartilage was detected in this fraction and there were no tubular structures of $>0.1 \mathrm{~mm}$ diameter. L.ungs of the three 60-day-old fetuses were not separated into lobes and were either dissected or left undissected. yielding three tracheas, two pleuras, two nondissected parenchymas and one dissected parenchyma. In the 125-day group one trachea and one middle lobe were not available for analysis.

Biochemical analysis. Approximately $8 \mathrm{mg}$ of dry tissue were weighed twice on a Mettler $A C 10()$ balance and digested twice with papain at $65^{\circ} \mathrm{C}$ for $24 \mathrm{~h}$. DNA was determined (23). An aliquot was hydrolyzed with $6 \mathrm{M} \mathrm{HCl}$ at $110^{\circ} \mathrm{C}$ for $72 \mathrm{~h}$. Collagen was measured as hydroxyproline (24) without making corrections for hydroxvproline contained in elastin fapproximately $1 \%$ (25)]. Elastín was determined by measuring desmosine by RIA after cellulose chromatography and acetylation (18). Mean recovery of desmosine standards subjected to three separate chromatographic separations was $104 \pm 10 \%$ (mean $\pm \mathrm{SD}$ ) $.91 \pm$ $6 \%$, and $91 \pm 15 \%$. respectively. Inter- and intraassay variability in four RIA assays of standards $(n=4 \times 12)$ were less than 7 and $5 \%$, respectively, in the midrange of the assay.

Data analysis: Concentrations of desmosine, hydroxyproline. and DNA are given per mg dry weight. The influence on the concentrations of desmosine, hydroxyproline, and DNA of gestational age and site (pleura, trachea, dissected, or nondissected parenchyma and upper middle or lower lobe) were analyzed with general linear model procedures on an IBM 4341 computer using SAS (SAS 1982. SAS Institute Inc.. Cary. NC). Tukey's test for multiple comparisons was used as appropriate. $p$ values of $>0.05$ were considered nonsignificant.

\section{RESUL.TS}

Desmosine concentration. Desmosine concentration increased 13-, 17-, 63-, and 11 -fold between day 60 and term in nondis- 
Table 1. Age and wt of fetal sheep (mean \pm SEM)

\begin{tabular}{cccc}
$\begin{array}{c}\text { Age (days) } \\
\text { (range) }\end{array}$ & $n$ & Body wt $(\mathrm{g})$ & Lung wet wt $(\mathrm{g})$ \\
\hline 60 & 3 & $46 \pm 8$ & $1.4 \pm 0.3$ \\
$(55-65)$ & & $299 \pm 28$ & $11.9 \pm 1.5$ \\
75 & 3 & $966 \pm 177$ & $32.6 \pm 4.9$ \\
$(75)$ & & & \\
100 & 4 & & \\
$(98-103)$ & & & \\
110 & 3 & $1457 \pm 75$ & $81.5 \pm 13.9$ \\
$(108-110)$ & & $3285 \pm 159$ & $94.4 \pm 5.9$ \\
125 & 3 & $2888 \pm 115$ & $129.5 \pm 8.2$ \\
$(122-127)$ & & & \\
137 & 3 & & \\
$(135-140)$ & 3 & $6021 \pm 578$ & \\
147 & 3 & & \\
$(146-149)$ & & &
\end{tabular}

sected parenchyma, pleura and trachea, respectively $(p<0.0001$, Fig. 1). Desmosine concentration was higher in pleura and trachea than in parenchyma $(p<0.0001)$ and higher in nondissected than in dissected parenchyma $(p<0.001)$. Desmosine concentration was highest in the trachea up to day 110 and highest in the pleura thereafter due to a more marked increase in the pleura than in any other compartment. The ratio between desmosine in dissected and in nondissected parenchyma was 0.43 on day 75 increasing to 0.74 by day 137 and plateauing at 0.70 on day 147 (interaction age $*$ dissected or nondissected $p=$ 0.04 between day 75 and 137 and $p=0.07$ between day 75 and 147), i.e. the rate of increase in desmosine concentration was higher in the dissected than in nondissected tissue (see "Discussion"). No significant differences were found between lobes (not shown).

Hydroxyproline concentration. Hydroxyproline concentration increased 2.1-, 1.8-, 5-, and 3-fold between day 60 and term in nondissected parenchyma, dissected parenchyma, pleura, and trachea, respectively ( $p<0.0001$, Fig. 2). Hydroxyproline concentration was higher in pleura and trachea than in parenchyma $(p<0.0001)$ and higher in nondissected than in dissected parenchyma $(p<0.0001)$. Hydroxyproline concentration was highest in trachea up to day 100 , similar to pleura on days 110 to 137 , and highest in pleura on day 147 . The ratio between hydroxyproline concentration in dissected and in nondissected parenchyma decreased steadily from 0.74 on day 75 to 0.59 at term (interaction age $*$ dissected or nondissected, $p<0.0001$ ), i.e. the rate of increase of hydroxyproline concentration was higher in nondissected than in dissected parenchyma (see "Discussion"). There was a general trend between days 75 and 147 for hydroxyproline concentration to be higher in the upper lobes than in the middle and lower lobes $(p<0.01$ between upper and middle and upper and lower lobes in dissected tissue and $p=0.03$ between upper and lower lobes in nondissected tissue). This trend was not observed at all ages and statistically significant only on day 125 if both dissected and nondissected tissue was analyzed together ( $p=0.02)$ (Fig. 3).

DNA concentration. DNA concentration in parenchyma was highest on day 125 ( $p<0.01$ versus days 100, 137, 147 and $p<$ 0.05 versus days 75 and 100$)$ and lowest on day $147(p<0.01$ versus all other ages) (Fig. 4). DNA concentration was highest in dissected parenchyma $(p<0.0001$ versus nondissected parenchyma, pleura, and trachea) and higher in pleura than in trachea $(p<0.002)$. DNA concentration tended to be higher in the lower lobes than in the upper lobes (Fig. 3). This was statistically significant only in nondissected tissue when all ages between day 75 and term were analyzed together $(p<0.01)$.

There was no difference in the concentrations of desmosine, hydroxyproline, or DNA between lungs of male and female fetuses.

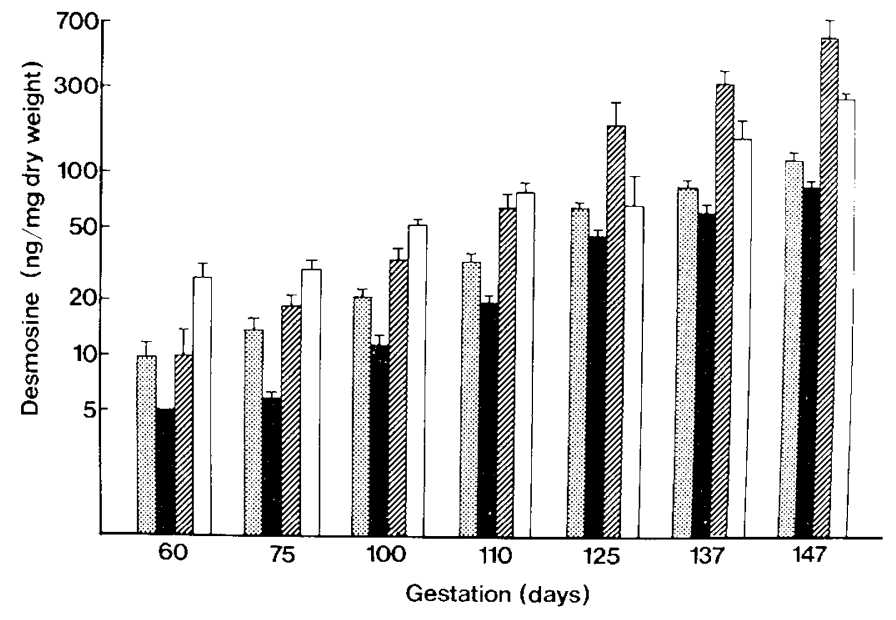

Fig. 1. Elastin (desmosine) concentrations in nondissected lung parenchyma (stippled bars), dissected parenchyma (solid bars), pleura (hatched bars), and trachea (open bars) between day 60 of gestation and term in fetal sheep. Note logarithmic scale (mean \pm SEM).

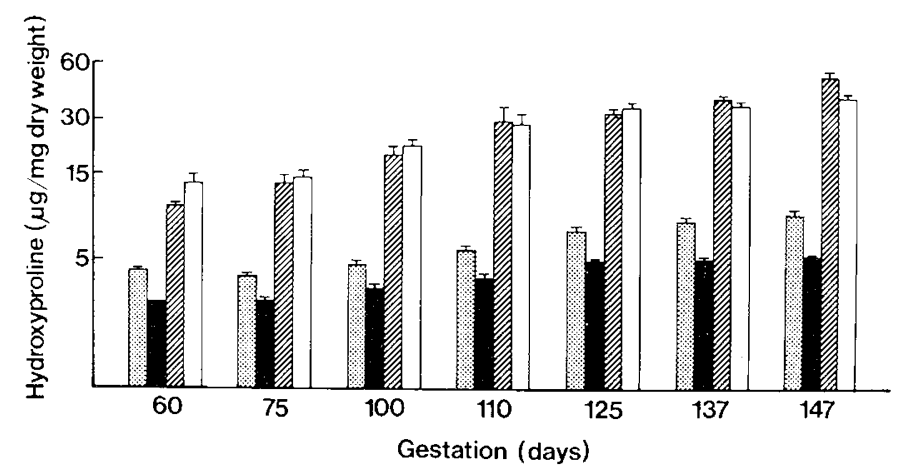

Fig. 2. Collagen (hydroxyproline) concentrations in fetal sheep lung between day 60 of gestation and term. Symbols and scale as in Figure 1 (mean \pm SEM).

\section{DISCUSSION}

The present study describes distinctive time courses of accumulation of elastin and collagen in various structural components of the lungs of fetal sheep. Lung parenchyma was separated into "nondissected" tissue containing "gas-exchange tissue" as well as large conducting airways and vessels rich in collagen and elastin and into "dissected" tissue containing only "gas-exchange tissue" and probably, particularly in early gestation, future small conducting airways (see "Methods"). As would be expected from macroscopic and microscopic observations, the concentrations of elastin and collagen were highest in pleura and trachea and lowest in dissected parenchyma at all gestational ages while the reverse was true for DNA concentration representing cellularity $(1-3)$.

In all compartments, the rate of accumulation of elastin was greater than that of collagen which is in accord with biochemical findings in parenchyma in lungs of rats and foals $(15,16,18$, 26). Histological and biochemical studies have linked the period of alveolization with a period of particularly rapid accumulation of elastin in all species so far studied $(2-5,15-18,27-30)$. In the rat, the steep rise in elastin concentration occurs during the period of alveolization $(15-18,28,29)$. In the sheep, this event appears to commence earlier, between days 100 and 110 (Fig. $1)$, i.e. during the late canalicular stage of morphogenesis $(2,3)$. Other dissimilarities in ontogenesis between the rat and the sheep have been reported, particularly the absence of a distinct saccular period in the sheep (2) and differences in the morphogenesis of 


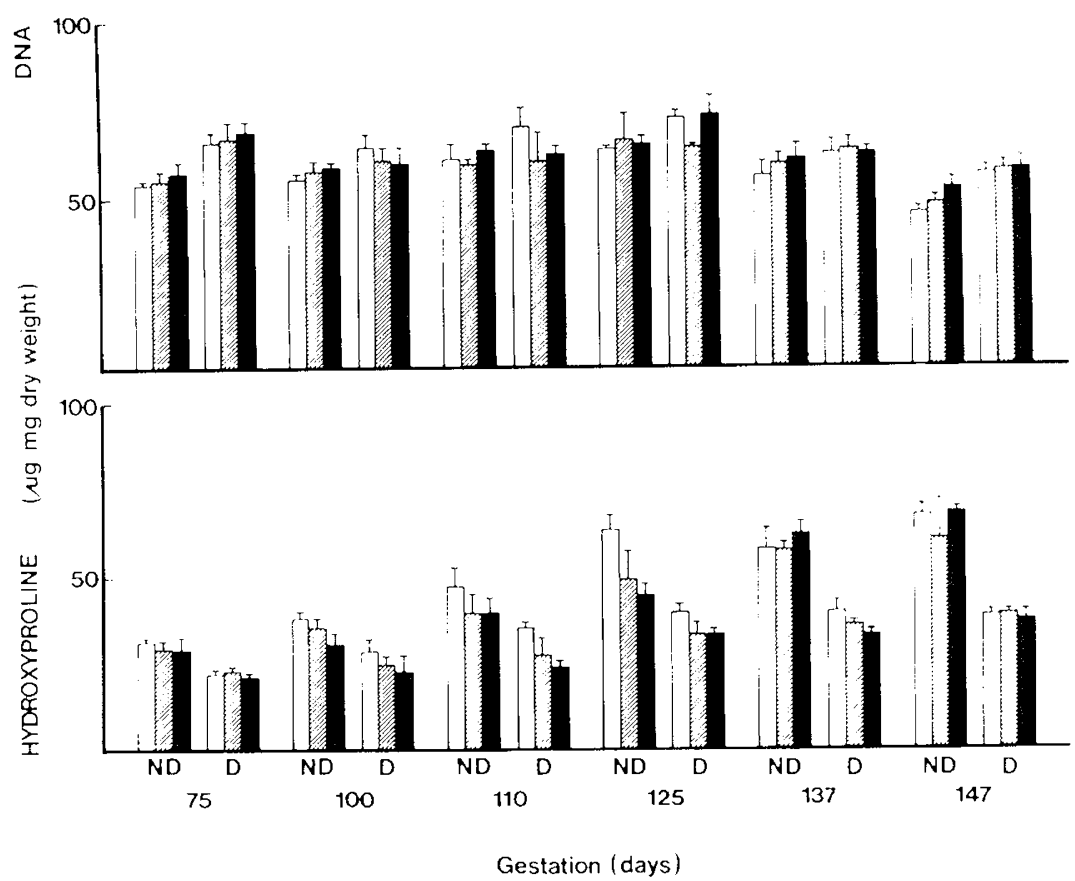

Fig. 3. DNA concentration and hydroxyproline concentration in upper lobes (open hars). middle lobes (hathed hars). and lower lobes (wolid hars) in nondissected $(N I)$ ) parenchymal lung tissue and in dissected $(D)$ parenchymal lung tissue (i.e. free from tubukar structures of $>0$ ). 1 mm diameter) (mean \pm SF $M$ )

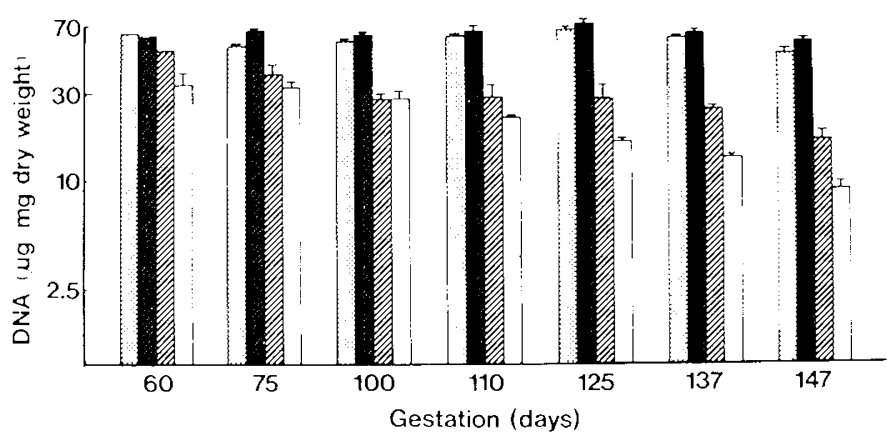

Iïg. 4. I NA concentrations in fetal sheep lung between Day 60 of gestation and term. Simbols and scale as in Figure 1 (mean \pm SIM).

the alveolar septa (3). However, the observed peak in D) NA concentration on day 125 is comparable to the peak in $[\mathrm{H}]$ thymidine labeling during the early alveolar period in the rat lung (31).

There was a general but inconsistent trend for collagen concentration to be higher in the upper lobes than in the lower lobes and a reverse trend for IDNA concentration. This confirms our impression gained at dissection of the presence of a tough fibrous structure extending between the pleura and the central airways in many upper lobes (32). Conversely, in many lungs. the lower lobe was particularly easy to dissect, which is consistent with a higher I)NA and lower collagen concentration. Preliminary studies showed no clear-cut differences in collagen concentrations between control and peripheral parts of lung lobes (Schellenberg $J-C$. I iggins ( $3($. unpublished data) suggesting that the mid-lobe sections used in this study are a reasonable reflection of the structure of the whole lobe.

The fetal lung appears to have little importance in utere but assumes a vital function immediately after birth. Maturational events preparing the lung for its postnatal role take place in the latter part of pregnancy (33). This is well documented for surfactant which is synthesized and secreted at increasing rates toward the end of gestation $(7,33)$. Since other components that are essential for normal neonatal lung function may also increase more rapidly toward term. We suggest that the mechanical function of elastin and collagen after birth may be deduced in part from their rates of accumulation before birth. The rate of clastin accumulation was greater in dissected than in nondissected parenchyma while the reverse was true for the rate of collagen accumulation. findings that are consistent with the development of a rigid collagenous structure of the central airways and vasculature and of a distensible peripheral "gas-cxchange tissue" relatively rich in elastin (34). The high rate of increase in clastin and collagen concentration in the pleura was maximal between day 125 of gestation and term. This is consistent with a major role for clastin in visceral pleura and hence of an important contribution of the visceral pleura itself to neonatal lung mechanics. perhaps by stabilizing lobe shape as has been suggested recently in adult dogs $(35)$.

Acknowledgment. The authors thank Alistair Stewart. Department of Community Health. Eniversity of Auckland. for help with statistics.

\section{RIHERINOHS}

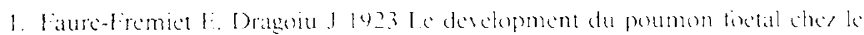
mouton. Arch Anat Microse Morphod I:p 19:411 47.4

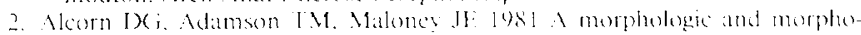

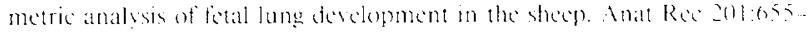
667

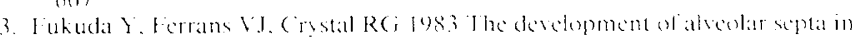
fetal shecp lung. An ultrastructural and immunohistechemical study. Am I Anat $167: 405-4,24$

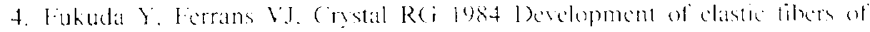

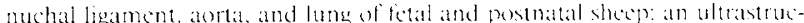
tural and cectron microscopic immunohistochemical study. Im I Anat $17(0: 597-620$

- Fierer J 1983 I Itrastructural studes of developing pulmonary alventar septal clastin. Ad lap Med Biol ?y:il it

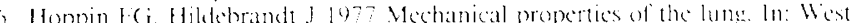

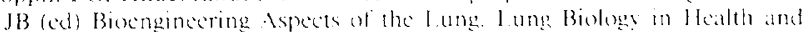

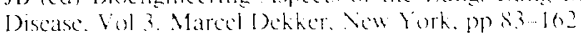

7. Schellenberg Je logs the development of connective tisste and its role in pulmonary mechanics. In: lohnston B. (iluchman PI) (con) Respiratury control and l.ung Development in the fetus and Vewhorn. Reproductive 
and Perinatal Medicine, Vol 3. Perinatology Press, Ithaca, NY, pp 3-62

8. Shibahara S, Davidson JM, Smith K, Crystal RG 1981 Modulation of tropoelastin production and elastin messenger ribonucleic acid activity in developing sheep lung. Biochemistry 20:6577-6584

9. Davidson JM, Shibahara S, Smith K, Crystal RG 1981 Developmental regulation of elastin synthesis. Connect Tissue Res 8:209-212

10. Foster JA 1982 Elastin structure and biosynthesis: an overview. Methods Enzymol 82:559-570

11. Emery JL 1970 The postnatal development of human lung and its implications for lung pathology. Respiration 27(suppl):41-50

12. Kida K, Thurlbeck WM 1980 The effects of beta-aminoproprionitrile on the growing rat lung. Am J Pathol 101:693-710

13. Loosli CG. Potter EL 1959 Pre- and postnatal development of the respiratory portion of the human lung. Am Rev Respir Dis 80:5-23

14. Hodel C 1968 Die fetale Entwicklung des elastischen Lungengerustes beim Menschen. Acta Anat 71:53-66

15. Powell JT, Whitney PL 1980 Postnatal development of rat lung. Changes in lung lectin, elastin, acetylcholinesterase and other enzymes. Biochem 188:1-8

16. Nardell EA, Brody JS 1982 Determinants of mechanical properties of rat lung during postnatal development. J Appl Physiol 53:140-148

17. Myers B, Dubick M, Last JA, Rucker RB 1983 Elastin synthesis during perinatal lung development in the rat. Biochim Biophys Acta 761:17-22

18. Schellenberg JC, Liggins GC 1987 Growth, elastin concentration and collagen concentration of perinatal rat lung: effects of dexamethasone. Pediatr Res 21:603-607

19. Richardson C, Herbert CN, Terlecki S 1976 Estimation of the developmental age of the ovine fetus and lamb. Vet Rec 99:22-26

20. Richardson $\mathrm{C}$, Herbert $\mathrm{CN} 1978$ Growth rates and patterns of organs and tissues in the ovine fetus. $\mathrm{Br}$ Vet $\mathrm{J}$ 134:181-189

21. Liggins GC, Schellenberg JC, Finberg K, Kitterman JA, Lee CH 1985 The effects of $\mathrm{ACTH}_{1-24}$ or cortisol on pulmonary maturation in the adrenalec- tomized ovine fetus. J Dey Physiol 7:105-111

22. Kitterman JA, Liggins GC, Campos GA, Clements JA, Forster CS, Lee CH Creasy RK 1981 Prepartum maturation of the lung in fetal sheep: relation to cortisol. J Appl Physiol 51:384-390

23. Burton K 1956 A study of the conditions and mechanisms of the diphenylamine reaction for the colorimetric estimation of deoxyribonucleic acid Biochem J 62:315-323

24. Stegemann H, Stalder K 1967 Determination of hydroxyproline. Clin Chim Acta 18:267-273

25. Paz MA, Keith DA, Gallop PM 1982 Elastin isolation and crosslinking. Methods Enzymol 82:571-587

26. Barnard K, Leadon DP, Silver AI 1982 Some aspects of tissue maturation in fetal and perinatal foals. J Reprod Fertil 32(suppl):589-595

27. Collet AJ, Des Biens G 1974 Fine structure of myogenesis and elastogenesis in the developing rat lung. Anat Rec 179:343-360

28. Burri PH 1974 The postnatal growth of the rat lung. III. Morphology. Anat $\operatorname{Rec} 180: 77-98$

29. Meyrick B, Reid L 1982 Pulmonary arterial and alveolar development in normal postnatal rat lung. Am Rev Respir Dis 125:468-473

30. Keeley FW, Fagan DG, Webster SI 1977 Quantity and character of elastin in developing human lung parenchymal tissues of normal infants and infants with respiratory distress syndrome. J Lab Clin Med 90:981-989

31. Kauffman SL, Burri PH, Weibel ER 1974 The postnatal growth of the rat lung. II. Autoradiography. Anat Rec 180:63-76

32. McLaughlin RF, Tyler WS, Canada RO 1961 Subgross pulmonary anatomy in various mammals and man. JAMA 175:694-697

33. Kitterman JA 1984 Fetal lung development. J Dev Physiol 6:67-82

34. Weibel ER, Gil J 1977 Structure function relationships at the alveolar level. In: West JB (ed) Bioengineering Aspects of the Lung. Lung Biology in Health and Disease, Vol 3. Marcel Dekker, New York, pp 1-81

35. Oldmixon EH, Hoppin FG 1984 Comparison of amounts of collagen and elastin in pleura and parenchyma of dog lung. J Appl Physiol 56:1383-1388 